\title{
The Science of Self, Mind and Body
}

\author{
Sung Jang Chung \\ Morristown-Hamblen Healthcare System, Morristown, USA \\ Email: sung.chung@comcast.net
}

Received April 30 $0^{\text {th }}$, 2012; revised May 29 ${ }^{\text {th }}$, 2012; accepted June $12^{\text {th }}, 2012$

\begin{abstract}
A relationship among self, mind and body in humans is still not clearly known in philosophy and science because of lack of human data that would enable to objectively explain it. Teachings related to their relationship in religions have been given to humanity in general in terms of subjective words. Consequently, philosophers and scientists have been investigating to find objective proofs related to their relationship. The author proposed a theory in his book (2009) that there are in a human individual two selves, one, the inner self (the true self) and one, the physical self (the false self) that coexist in one individual person. McGonigal (2012) published her book in which she described two minds or two selves in one human individual, naming them "I WILL" and "I WANT" self on the basis of extensive studies on adult subjects. More recent researches in neuroscience using functional magnetic resonance imaging (fMRI) discovered that the prefrontal cortex of the human brain performs self-control, emotion regulation and guiding behaviors with morality, future goals and rules. The author compared characteristic aspects of the inner and physical selves of Chung with the "I WILL" and "I WANT" selves of McGonigal. There is a remarkable good agreement between the inner and physical selves of Chung and the "I WILL" and "I WANT" selves of McGonigal. The author proposes a theory in this study that the inner and physical selves correspond to the "I WILL" and "I WANT" selves, respectively, and that the inner self, the true self, controls the physical self, the false self, interacting with the prefrontal cortex of the human brain.
\end{abstract}

Keywords: Self; Mind; Free Will; Evolution; Neuroscience; Prefrontal Cortex; Probacent Model

\section{Introduction}

A clear relationship among self, mind and body in humans is still not known in philosophy and science because of lack of human data that would enable to explain it objectively (Gusnard, 2009; Vacariu, 2011; Dresp-Langley \& Durup, 2012).

Most philosophical definitions of self (Descartes, Locke and Hume) are expressed in the first person (Gaynesford, 2006). The philosophy of self defines the essential qualities that make one person distinct from all others. The self is the agent being the source of consciousness, and responsible for the thoughts of mind and actions of body of an individual, enduring through time. The particular characteristics of the self determine its identity. Descartes who has been dubbed as the "Father of the Modern Philosophy" is best known for the philosophical statement "Cogito ergo sum" (English: I think, therefore I am) (Wikipedia, 2012).

Teachings in religions concerning their relationship among self, mind and body have been given to humanity generally in terms of subjective words. It is taught in religions that the soul (self) leaves the body at death and would be born on the Other Side, the spiritual world, implicating ontologically existence of soul (self) and non-soul (non-self, body, world, and universe).

Consequently, scientists have been investigating to find objective proofs in the realm of mysterious complex fundamental problems and questions, using animals, especially primates including humans. Psychologists, psychiatrists and neuroscientists have been recently doing researches with help of functional magnetic resonance imaging (fMRI) and positron emission tomography (PET) to study the brain structures and functions, particularly the prefrontal cortex of the brain (Sapolsky,
2004; Miller \& Cohen, 2001; Greene, 2001; Banks et al., 2007; Rilling \& Insel, 1999; Braun et al., 1998; Herman et al., 2005; Bauer et al., 1998; Gusnard, 2009). The prefrontal cortex is its largest, in both absolute and relative terms, in the human among anthropoid primates (Rilling \& Insel, 1999; Sapolsky, 2004).

The author attended a weekly math seminar when I was a graduate student at the Seoul National University in Seoul, Korea. We encountered a hard and unsolved math problem in a seminar. I continued to attempt to solve the problem after the seminar for about a month whenever I had a free time. One night, I dreamed about the same math problem. To my surprise, I got a solution of the problem in my dream. I was overwhelmed with joy to see the problem was perfectly solved. I woke up at the moment of feeling joy. I presented the solution of the math problem at the next seminar. It seemed to the author that my conscious and subconscious minds were connected and worked together in concert to solve the math problem.

One time, I encountered another difficult mathematical problem that was not solved in a dream but was solved, I believe, in my subconscious mind. It was a hard differential calculus problem in my research that was aimed to find a general mathematical formula of hazard rate of a formula that expresses a relationship among intensity of stimulus, duration of exposure and occurrence of response in biological phenomena (Chung, 2009). One day, I went a health spa with my family in Atlanta, Georgia. After parking our car, we walked in yard decorated with a beautiful flower garden. I enjoyed the beauty of the garden while walking. At that moment, the math problem suddenly crossed my mind. I started to try to solve it in my mind while walking. I instantly got an idea for its solution, like a flash in my mind. I hurried to the lobby of the health spa, where I got a 
pencil and paper and wrote down the calculation I had done a moment before. The difficult-looking problem was clearly and correctly solved. It seems to me that my subconscious mind continued to reason and perfectly solved the problem and then suddenly transferred the solution to my conscious mind (Chung, 2009). I published the solution of the math problem in the International Journal of Biomedical Computing in 1995 (Chung, 1995).

Human beings are composed of the body made of material matter, and the conscious mind. My manifest conscious mind while awake could not solve the difficult math problems but my subconscious mind solved the problems. The master who acted in the mathematical reasoning in my manifest consciousness and sub-consciousness was a personality "I". It seems logical to infer that there is an independent self with self-awareness in my subconscious mind. I name this self the "inner self". There seems to be another self in my manifest consciousness that is felt as "I", and closely associated with my bodily functions and my brain activities, sensing the world around the body through sense organs. The latter self is associated with the physical body; I name it the "physical self". The conscious mind seems to be occupied by the physical self and/or the inner self. The conscious mind can be abolished by anesthetic drugs, hypoxemia, hypoglycemia, coma or injury.

The inner self has conscience, will power, morality, creative power, mathematical computing reasoning, and future plan and high goals. The physical self acts on the basis of pleasure, desire, and instinct for living without future goal or plan. At death when the brain and body deteriorate, disintegrate and return to Earth, the physical self disappears permanently. The inner self is considered to leave the physical self/body and is believed to continue to live and return to the spiritual world. Therefore, the inner self is the true self, the real self. The physical self is the false self, the non-real self.

It seems true that a human individual has two personalities, two selves: the inner self (the true self) and the physical self (the false self) (Chung, 2009; Hawkins, 2002; Bailey, 2006). The inner self is created from and by the Creator and lives on the Earth as a co-creator. The inner self is connected through the super self to the Creator (Chung, 2009). The physical self is created by the Creator. An artist (the inner self) can create art products. A composer can create music. However, the art product or the music cannot create the artist or the composer. The inner self can control the physical self's behavior.

In Brad Steiger's One with the Light (1994) and Guy Lyon Playfair's Twin Telepathy (2002), both authors described the same extraordinary case of near-death experience. Both authors described the true story of a physician. According to this anonymous physician, shortly after midnight, the doctor was stricken with acute gastroenteritis and apparently suffered a cardiac arrest and unconsciousness. He was subsequently resuscitated by another doctor. He experienced an extraordinary phenomenon during the period from the cardiac arrest to recovery. He saw two personalities, A and B, that he felt to be himself: one personality, $\mathrm{B}$, linked to his body and the other personality, A, free from the body. The B personality faded and disappeared as the physical body deteriorated further. The A personality was separated from the other personality B and leaving his physical body. The A personality was conscious outside the body and could observe his body lying in bed. He realized that he could also see everything in his house. After resuscitation with a camphor injection, the A personality re- turned to his physical body. Once he was back, all clear vision of everything disappeared.

In the above published case of near-death experience, it seems most likely that what occurred was that the inner self (the A personality) left the physical body. The inner self saw the other part of the self, the physical self (the B personality); this remained attached to the body and then disintegrated as the brain and the body ceased to function; then the physical self was unconscious in the physical world. On the basis of the above true story, I infer that both the inner self and the physical self are unknowably superimposed and coexist in the individual self of a man.

McGonigal (2012), a psychologist at Stanford University published her book, The Willpower Instinct that explains the scientific reality of willpower on the basis of a large amount of scientific researches on humans, and discovered facts. She clearly described that human mind is not one unified self but multiple selves who compete for control; our self has two selves, that is, two minds: one wiser mind with a higher purpose that controls the other impulsive mind that wants instant gratification. She named the first mind "I WILL" self, and the second mind "I WANT" self.

According to some neuroscientists, we have one brain but two people living inside our mind; one person acts on impulses and seeks instant gratification, and the other person controls impulses and delays gratification to protect our long-term goals (McGonigal, 2012).

Baumeister and Tierney (2011) published their book titled “Willpower: Rediscovering the Greatest Human Strength". The authors described extensively about scientific aspects of the will power in self-control in our lives and relevant informative scientific researches.

Sapolsky (2004), a neurobiologist at Stanford University reported on the basis of findings in contemporary neuroscience that the role of the prefrontal cortex (PFC) of the human brain is cognitive control, emotion regulation, control of impulsive behavior and moral reasoning.

Miller and Cohen (2001) at Stanford University proposed an integrative theory of prefrontal cortex function of cognitive control, goals and rules.

Kluger (2012) published an article titled "Getting to No: The Science of Building Willpower" that described the willpower, and the "I WILL, I WAN'T, I WANT" theory of McGonigal and the role of the frontal cortex of human brain, and relevant recent discoveries in psychology and neuroscience.

The author's scientific research in biomedicine was initiated in Korea and its summary was published in the Republic of Korea Journal of the National Academy of Sciences in 1960. The research was continued in the United States. Scores of articles were published in international and American journals (Chung, 1986, 1988, 1991, 1995, 2007, 2011a, 2011b, 2012). The original goal of my research has been to find a general mathematical model of "probacent"-probability equation that would calculate the probability of safe survival in humans and other living organisms exposed to any harmful or adverse circumstances, overcoming the risk.

The author proposed a theory based on philosophical contemplation and reasoning, and relevant recent scientific discoveries that a human individual is a person in whom the physical self, the false self and the inner self, the true self coexist as oneness (Chung, 2009).

To my knowledge, there seem to be no scientific articles in 


\section{S. J. CHUNG}

the literature of philosophy and science that clearly explain the relationship among self, mind and body in humans (Gusnard, 2009; Vacariu, 2011).

In this study, an attempt is made to propose a theory that the inner, true self and the physical, false self coexist in humans; and correspond to the "I WILL" and the "I WANT" selves of McGonigal (2012), respectively; and in addition, the inner self controls the physical self, interacting with the prefrontal cortex of the brain.

\section{Materials and Methods}

McGonigal (2012), a psychologist at Stanford University published her book, The Willpower Instinct: How Self-Control Works, Why It Matters and What You Can Do to Get More of It. As a health psychologist, McGonigal specially studied willpower in self-control to help her students make positive changes in their lives, in strengthening self-control, weight loss, stress reduction, controlling emotion, conquering procrastination, identifying goals, professional success and so forth.

Investigative observations were made in her studies concerning presence or absence of willpower in self-control, reason, morality, goals, plan for future etc.

She described in her book results of her extensive scientific researches on human adult subjects and her comprehensive review of newest relevant data from recent researches in psychology and neuroscience.

She discovered in her researches that a human self has two minds: one impulsive mind that wants instant gratification, and one super and wiser mind that does self-control and guides behavior. She named the former "I WANT" self and the latter "I WILL" self, suggesting the human nature of two selves.

In this study, the author did comparison of characteristic aspects of the inner versus physical self of Chung (2009) and the “I WILL” versus “I WANT” self of McGonigal (2012).

In addition, a similar comparison of the inner versus physical self with the functions of the prefrontal cortex (PFC) and other brain structures reported by Sapolsky (2004), and Miller and Cohen (2001).

\section{Results}

Table 1 shows a remarkable good correlation or agreement between characteristic aspects of the inner versus physical self

Table 1.

Comparison of characteristic aspects of the inner versus physical self (Chung, 2009) with those of the "I WILL" versus "I WANT" self (McGonigal, 2012).

\begin{tabular}{|c|c|c|c|c|}
\hline Characteristic aspects & Inner self & “I WILL” self & Physical self & “I WANT" self \\
\hline Self-control & + & + & - & - \\
\hline Reason & + & + & - & - \\
\hline Morality & + & + & - & - \\
\hline Willpower & + & + & - & - \\
\hline Conscience & + & + & - & - \\
\hline Responsibility & + & + & - & - \\
\hline Wisdom & + & + & - & - \\
\hline Goals & + & + & - & - \\
\hline Plan for future & + & + & - & - \\
\hline Creative work & + & + & - & - \\
\hline Nature & Good & Good & Evil & )$^{* *}$ \\
\hline Math reasoning & + & + & - & - \\
\hline Response time & Control timing & Control timing & Instant & Instant \\
\hline Feeling & Calm & Calm & Restless & Restless \\
\hline Social rules & + & + & - & - \\
\hline Sacrifice & Altruistic & Altruistic & Egoistic & Egoistic \\
\hline Desire for pleasure & Delay or suppress & Delay or suppress & Instant gratification & Instant gratification \\
\hline Compassion & + & + & - & - \\
\hline Memory retrieval & + & + & - & - \\
\hline Meditation & + & + & - & - \\
\hline After death & Live & )$^{*}$ & Disappear & Disappear \\
\hline Selfhood & True & )$^{*}$ & False & )$^{*}$ \\
\hline Precognitive dream & + & )$^{*}$ & - & )$^{*}$ \\
\hline
\end{tabular}


of Chung (2009) and the "I WILL" versus "I WANT" self of McGonigal (2012). Both the inner self and the "I WILL" self have the willpower, morality, creative power and mathematical reasoning; and controls the physical self and the "I WANT" self that appear to act for pleasure, desire, living, and instant gratification, respectively.

Table 2 shows a good correlation between characteristic aspects of performance of the inner self and the prefrontal cortex of the human brain. The inner self and the "I WILL" self seem to be able to control the physical self and the "I WANT" self by interacting with the prefrontal cortex and then regulating the other brain structures from the perspective of Salpowsky (2004), and Miller and Cohen (2001) in neuroscience.

McGonigal created a course for Stanford's Continuing Studies program called "The Science of Willpower" based on results of her researches.

\section{Discussion}

Table 1 shows a remarkable good correlation or agreement between the inner versus physical self and the "I WILL" versus "I WANT" self in terms of characteristic aspects, respectively. Table 2 reveals similarly a good correlation between characteristic aspects of performance of the inner self and the prefrontal cortex of the human brain.

The inner self seems to be the true and real self with free will that does self-control, modulate behavior with goals and rules, morality, creative work, controlling the physical self that is primarily associated with the brain and the physical body, sensing the external world through sense organs and responding to the world. The physical self/body behaves on the basis of pleasure-desire and for living, being impulsive (Chung, 2009).

Hsun Tzu proposed a theory of evil human nature $(\mathrm{Hu} \&$ Guo, 2011) that contends that the human nature is evil inborn. Evil results from uninhibited desires for living. Selfishness is inborn in human nature. It seems to the author that the evil human nature is applicable to the physical self/body. Mencius believed in the innate goodness of man. He supported the good human nature in Confucianism (Hu \& Guo, 2011). The good human nature of Mencius seems to be applicable to the inner self. The perspective of the inner versus physical self seems to solve the dilemma of the two contradictive theories regarding the human nature.

Perlovsky, a physicist and researcher at Harvard University

\section{Table 2.}

Comparison of characteristic aspects of performance of the inner self (Chung, 2009) and the prefrontal cortex of the human brain (Sapolsky, 2004; Miller \& Cohen, 2001).

\begin{tabular}{lcc}
\hline Characteristic aspects & The inner self & The prefrontal cortex \\
\hline Cognitive control & + & + \\
Goals & + & + \\
Rules & + & + \\
Behavior control & + & + \\
Emotion regulation & + & + \\
Moral reasoning & + & + \\
Control of impulsive behavior & + & + \\
Math reasoning & + & + \\
Memory retrieval & + & + \\
\hline
\end{tabular}

+ : present. published an article, "Free will and advances in cognitive science” (2012). He thoroughly examined recent discoveries in cognitive science. He supports free will of mind that is not reducible. "Free will is fundamental to morality, intuition of self, and normal functioning of society". "Free will can be scientifically accepted along with scientific monism”.

It seems to the author that freedom of will is indispensable to self-control by the inner self. The physical self/body seems to carry out bodily reactions determined by physical and chemical laws and so impulsive in its behavior; the physical self seems to have no free will from the viewpoint of the scientific monism (determinism) so that states of the mind are produced by material processes in the brain. The perspective of the inner versus physical self/body offers a possible resolution of the dilemma of the contradictive scientific monism and the free will in human mind. The physical self fades and disappears when the brain and body deteriorate and disintegrate at death.

Human actions are done by conscious minds occupied by the physical self and/or the inner self. Therefore, it is extremely important that the inner self controls the physical self every moment by positively occupying the conscious mind, directing physical self/body's behaviors with free willpower. As Buddha said, "One who conquers himself is the supreme conqueror, rather than those who fight in the battlefield and conquer a million enemies" (Buddhism, 1987). I believe that the term "himself" here implies his own physical self as an enemy. As the guru, Yogananda (1982) said, "You are your own enemy, and you don't know it”. I believe that this means that your physical self is the enemy of your inner self. Hawkins (2002), a psychiatrist, wrote in his book that the human ego is actually not an "I" at all (the author's note: "I" means here to be the inner, real self); this illusion of apparently separate, individual "I" ego as his real "I" is the source of all human suffering (the author's note: "I" ego is the physical self).

It seems to me that the relationship between the physical self and the inner self is analogous to driving a car. The driver is the inner self, the true self and the steering wheel and engine are the physical self. The car structure is the physical body. The car is in a nearly automatic driving condition. The road is considerably narrow and winding, and supposed to represent the world full of temptations and illusions. The driver (the true, inner self) controls the steering wheel with reason, conscience, and willpower in guiding the car. The driver is constantly watching the car operated by the physical self. The driver (the inner self) must be alert and careful, ready to slow down, turn or stop the car at any moment if needed. The true, inner self is also endeavoring to be calm and feel his total responsibility in driving. The physical self would not be blamed for any wrong driving or accidents. The inner self (the driver) would be responsible under the law of society.

If the prefrontal cortex (PFC) is organically and/or functionally damaged and so the inner self cannot interact with the PFC and so cannot control it, in this case, the physical self/body would not be responsible for any wrong or illegal behaviors and acts because the physical self does not understand and differentiate right from wrong (incapable of cognitive control). This case seems similar to cases of the insanity defense in a criminal justice system. If the PFC is normal and fails to yield to control by the inner self and chooses anti-social wrong behaviors, then the inner self would be responsible for the wrong or illegal behavior or act. If someone with epilepsy strikes another person in the course of a seizure, "it is not him; it is his disease" (Sapolsky, 2004). The above cases seem to be analogous to the 
driving a car as above described: the inner self (self of an individual) is the driver and responsible in driving, and the steering wheel and engine with the car body that are the physical self/body (the PFC and other brain structures and the body) are not responsible. This contemplation is tacitly suggestive of the inner self (the real self) independently existing from the physical self/body.

Baumeister and Tierney (2011), and McGonigal (2012) recommended meditation in their books; meditation (Yogananda) helps for strengthening the willpower and health.

The inner self is believed to be created from and by the Creator, God (Holy Bible, Koran, Yoganada), being part of Creator, and so to be a co-creator with free willpower in the world. The physical self/body is created by the Creator and can be changed by His will. The inner self (soul) does not only control but also would be able to heal the physical self/body by his will united with the will of the Creator (Yogananda, 1946; Villoldo, 2000; Perlmutter \& Villoldo, 2011). The inner self seems to be connected through the super self to the Creator (Chung, 2009). Christianity teaches the doctrine of trinity of Holy Father, Holy Son and Holy Spirit. In Confucianism, there is a doctrine of the three origins of 10 and 5 and 1 Word in Kim Hang's book, the Book of Right Change, JeongYeok 正易 (Chung, 2010). 10 represents Moogeuk (Wu Chi), the NonUltimate, Creator; 5 Hwanggeuk (Huang Chi), the Ultimate Emperor, Saint; and 1 Taegeuk (Tai Chi), the Great Ultimate, Power of Creator. There seems to be an agreement between both doctrines of Christianity and Confucianism (Wilhelm, 1967; Chung, 2009, 2010). The author believes that Jesus, Buddha, Confucius, Kim Hang, Muhammad, Yogananda, Moses and other saints in human history are saints (the super self) and represent the Son of God. In human evolution, mankind seems to continue to evolve from the current human stage and society to stages of saints, the super self and an unimaginable, ideal society, the kingdom of heaven (Holy Bible, Jeong Yeok 正易), and to be united with the omniscient, omnipotent and omnipresent Creator, God; enlightenment, the self-realization (Yogananda, 1946, 1996; Villoldo, 2000; Chung, 2009, 2010; Perlmutter \& Villoldo, 2011).

Darwin's evolutionism seems to be applicable to the realm of the physical self/body and the creationism to the realm of the inner self (soul). The perspective of the inner versus physical self seems to provide a possible resolution to the evolutionism and creationism regarding human history (Patent, 2001; Chung, 2010).

Current theory in the human evolution holds that the modern human, Homo sapiens migrated from Africa to the Middle East about 120,000 years ago (The National Geography Society, 2007). According to the Book of Right Change, JeongYeok 正 易 written by Kim Hang who was a Korean scholar and a master of Confucianism, Buddhism and Taoism, the year 1884 A.D. was 118, 643 year (Chung, 2010).

The author had two unusual precognitive dreams during the World War II and the Korean War. Special dreams such as precognitive dreams that come true in reality are considered to be the work of the inner self (Chung 2009). The author wishes to describe his two dreams in order to share them with readers because of their rarity and possibly important philosophical implications.

\section{A Precognitive Dream in Prison during the World War II}

In 1944, Korea was under the suppressive colonial Japanese government. I was a medical student at the Keijo Imperial University College of Medicine (now the Seoul National University College of Medicine). I joined an underground organization for Korea's independence movement. The movement was detected by the police in December 1944. I was imprisoned after interrogation and inhumane torture in the Seodaemun Prison in Seoul in January 1945. It was a freezing cold winter. Epidemic typhus fever prevailed in the prison that winter of 1944-1945, infecting many prisoners. I heard that quite a number of patients died of typhus. I was one of the patients and placed in an isolation room without any medical treatment. I suffered high fever, headache, malaise, loss of hearing and vague consciousness. I eventually recovered from typhus fever and was transferred to a general prison cell.

One night in June 1945, I had an unusual dream. An old man in a gray Korean coat suddenly appeared in front of me in my dream. I fell to the ground face down and asked him, "When shall I be released from prison?”

He answered instantly, "The day is the thirty first". Then the old man disappeared, and at the same time I woke up from the dream. I believed that I had experienced a precognitive dream, and I began to wait for the thirty first day of the next month July. About one month later, I was unexpectedly released from prison on the exactly predicted date, July 31, 1945 (Chung, 2009).

\section{A Precognitive Dream in North Korea during the Korean War}

In 1950, when North Korea invaded South Korea, I was one of hundreds of South Korean physicians who were forcefully transported from South to North Korea by North Korean communist agents. My group of six South Korean physicians was sent to Hamhung, North Korea and ordered to treat patients at the Hamhung Provincial Hospital. I was assigned to treat general civilian outpatients. Inpatients were treated by other physicians. These inpatients included North Korean civilian and military patients.

Air raids by scores of US B-29 bombers in formation were daily getting severe. During the daytime, whenever siren signals of air raid were heard, we had to stop medical service work and immediately seek refuge in an air-raid shelter.

One night in September 1950, I had an unusual dream. I saw a wall calendar with a black printed number of the date in the middle of white paper. The number was a crystal-clear 13. That seemed to indicate that the date of the coming thirteenth day of October would be an especially important and critical day. The calendar then disappeared, and I saw a night scene. In the darkness of night, I was walking toward one direction with other people in a line.

I looked around both sides of the road. There was a flowing river on the left side, and a mountain on the right side. I said to a nearby nurse, "If we pass the thirteenth day tonight, we will survive and have good days ahead. Let's be patient. We have hope.”

The nurse appeared glad to hear me say it. After talking to the nurse, I woke up. I felt that the thirteenth day would be the coming October 13. I began to wait for that day. I believed that if I passed October 13 without any difficult events, I would have good days thereafter. I told actually my special dream to the other South Korean physician colleagues.

The great historical battle at Inchon Harbor involving the 
landing by UN and South Korean forces on September 15, 1950; recapture of the capital, Seoul, on September 27-28; crossing the $38^{\text {th }}$ parallel on October 9; and the northward advance of UN and South Korean forces, totally changed the situation of the war in the Korean peninsula (Gruenberg, 1959).

The long-waited day of October 13 came. An unexpected event took place. The communist agent responsible for the hospital ordered the entire staff of the Hamhung Provincial Hospital to gather at the hospital campus that evening to prepare to retreat north. Scores of North and South Korean doctors, nurses, and non-medical staff members then started to retreat north on foot in a formation of lines and groups, leaving the hospital and Hamhung City in the darkness of night.

I got out of Hamhung City for the first time. All of the hospital personnel were walking in line on a dark road leading north. I looked around at the surrounding natural scene while I walked. The Sungchun River was on my left side, and mountains were on my right side. It was an amazing event. The night scene and the date exactly matched the landscape and the number thirteen on the wall calendar in my dream a few weeks earlier. The coincidence of the dream and the reality was unbelievable beyond expression and convinced me to believe that the special dream was a precognitive dream and a revelation from heaven.

I spoke to a nurse who was walking beside me, as I had in my dream, I said, "Hello. If we pass the thirteenth day tonight, we will be free. Let's be patient tonight. We will have good days starting from tomorrow". The nurse was glad to hear me say it. I did not tell her about my dream. I just talked similarly to how I had done in my dream. I felt inexpressible joy and hope while I was walking. My heart was pounding with gratitude, wonder, and courage. The dream helped not only me but also other people in the war (Chung, 2009).

The above special precognitive dreams seem to be suggestive of the work of the author's inner self and further to reveal a possible glimpse into an unknown, timeless and non-local spiritual world.

Modern physics proved that matter is composed of energy, and form without solid matter. Matter is energy of vibrating waves of different frequencies. It seems to the author that neurons of the brain produces images composed of physical energy of vibrations of yet unknown frequencies that seem to produce mental-like images of unknown incomprehensive frequencies of vibratory energy. The inner self seems to be able to perceive this vibratory energy image produced by neurons at the end process in the neurons of the prefrontal cortex. The inner self also seems to be able to produce mental vibratory waves of unknown frequencies by mind that cause physical corresponding resonant-like vibratory waves of energy in neurons of the brain. In this way, the physical self and the inner self appear to mutually interact in the prefrontal cortex.

The fundamental elements of matter, electrons, protons, photons, quarks, leptons etc. are particles composed of energy and also simultaneously waves of certain frequencies, showing dual qualities. It seems to me that consciousness probably exists, inherently superposing to dual aspects of subtle particle and wave of each particle (Chung, 2009). Consequently, as aforementioned, self, especially the inner self is believed to be able to create energy and change matter.

Neurons of the brain require oxygen and glucose etc. for their normal functions. Hypoxemia, hypoglycemia, general anesthetic drugs, ischemic damage in stroke or coma caused by injury or infection can disrupt neuronal functions and abolish the consciousness. In these cases, the inner self cannot control the brain, the physical self/body, indicating a functional disconnection between the inner self and the physical self/body.

In Alzheimer's disease, if advanced and severe, the inner self cannot interact with and/or control the physical self because of pathologic changes in the brain (Richards \& Sweet, 2009). This suggests independent existence of the inner self being away from the physical self/body.

Vacariu (2011), a philosopher at the University of Bucharest proposed a theory of "epistemologically different worlds" (EDWs) in investigating the mind-body problem in humans. He stated that the human subjectivity, the "I" is knowledge. I may interpret his statement as follows: the inner self seems to correspond to the "I" and to have knowledge.

One case of the most famous patient in the history of neuropsychology, Phinneas Gage who was a railroad constructor, damaged his prefrontal cortices in an explosive accident made neuroscientists find enormous valuable information on the prefrontal cortices for human knowledge (Sapolsky, 2004; Gusnard, 2009). The selective destruction of the Gage's prefrontal cortex transformed Gage from a taciturn, reliable foreman in a railroad construction crew to a coarse, disinhibited, unstable individual who was never able to work (McMillan, 2000; Sapolsky, 2004).

The true story of the aforementioned English medical doctor who saw his two personalities in his near-death experience (Steiger, 1994; Playfair, 2002) and the true story of two unusual precognitive dreams as well as an unusual dream of mathematical reasoning and solution of math problems of the author seem to me to be hard to deny their truth merely because of their rarity or a small number if we take into consideration the case of a patient, Phinneas Gage in neuropsychology. In addition, the above findings suggest inconceivable potential power of the inner self and further possibly reveal mysterious transcendental truth with a glimpse into timeless and non-local spirit world (Yogananda, 1946; Villoldo, 2000; Chung, 2009).

Recent researches in neurobiology and neuroscience revealed enormous reciprocal synaptic connections between the prefrontal cortices and other brain structures of limbic system, amygdala, hypothalamus, hippocampus; nucleus accumbens, putamen, thalamus, substantia nigra, etc. (Sapolsky, 2004; Banks et al., 2007; Schultz et al., 2000; Rilling \& Insel, 1999; Herman et al., 2005). The animal's brain has less than 100 thousand neurons and in the human brain there are 100 billion or more neurons (Miller \& Cohen, 2001).

Neuroscientists discovered more recently that the prefrontal cortex (PFC) does cognitive control, emotion regulation, control of impulsive behavior, moral self-control, and guiding brain activities with goals and rules, using fMRI (Sapolsky, 2004; Miller \& Cohen, 2001; Greens et al., 2001).The prefrontal cortex receives information from sites throughout the rest of cortex. The nucleus accumbens is involved in pleasure and reward, using neurotransmitter, dopamine signaling to the prefrontal cortex. The prefrontal cortex sends inhibitory signals to the limbic system and amygdala, suppressing impulsive emotion and behavior (Sapolsky, 2004).

\section{Conclusion}

Results of recent researches by psychologists, psychiatrists, neurobiologists and neuroscientists are reviewed from the au- 
thor's perspective of the inner and the physical selves in human individuals.

A following theory is proposed in this study on the basis of the author's previous researches and relevant review of recent discoveries brought by psychologists, psychiatrists and neuroscientists:

1) A human individual is composed of the inner self and the physical self/body that seem to correspond to the "I WILL" self and "I WANT" self named by McGonigal (2012), respectively.

2) The inner self does self-control with conscience, reason, will power, morality and creative power; emotion regulation and guide behavior, supervising the physical self/body that senses through the sensory organ system, and responds to the external world, and that is impulsive, behaving for pleasuredesire and living.

3) The inner self is the true and real self; the physical self is the false self that would fades and disappears at death.

4) The inner self controls the physical self/body by interacting with the prefrontal cortex of the human brain.

\section{REFERENCES}

Bailey, A. (2006). The reappearance of the Christ. New York, NY: Lucas Publishing Company.

Banks, S. J., Eddy, K. E., Angstadt, M., Nathan, P. J., \& Phan, K. A. (2007). Amygdala-frontal connectivity during emotion regulation. Social Cognitive and Attentive Neruroscience, 2, 303-312. doi:10.1093/scan/nsm029

Baumeister, R. F., \& Tierney, J. (2011). Willpower: Rediscovering the greatest human strength. New York: The Penguin Press.

Braun, A. R., Balkin, T. J., Wesensten, N. J., Gwadry, F., Carson, R. E., Varga, M., Baldwin, P., Belenky, G., \& Herscovitch, P. (1998). Dissociated pattern of activity in visual cortices and their projections during human rapid eye movement sleep. Science, 279, 91-95. doi:10.1126/science.279.5347.91

Buddhism, (1987). The Dammapada. In J. Pelikan, (Ed.), Sacred writings. New York: Book-of-the-Month Club.

Chung, S. J. (1960). Studies on a mathematical relationship between stress and response in biological phenomena. Republic of Korea Journal of the National Academy of Sciences, 2, 115-162.

Chung, S. J. (1986). Computer-assisted predictive formulas expressing relationship amongmetrazol dose and time and mortality in mice. Computer Methods and Programs, 22, 275-289. doi:10.1016/0169-2607(86)90004-0

Chung, S. J. (1988). Formula predicting carboxyhemoglobin resulting from carbon monoxide exposure. Veterinary and Human Toxicology, 30, 528-532.

Chung, S. J. (1995). Formula expressing life expectancy, survival probability and death rate in life table at various ages in US adults. International Journal of Biomedical Computing, 39, 209-217. doi:10.1016/0020-7101(94)01068-C

Chung, S. J. (2007). Computer-assisted predictive formulas expressing survival probability and life expectancy in US adults, men and women, 2001. Computer Methods and Programs, 86, 197-209. doi:10.1016/j.cmpb.2007.02.009

Chung, S. J. (2009). Seeking a new world: A new philosophy of confucius and Kim Hang. Bloomington, IN: iUniverse.

Chung, S. J. (2010). The book of right change. JeongYeok (正易): A new philosophy of Asia. Bloomington, IN: iUniverse.

Chung, S. J. (2011a). Predictive formulas expressing relationship among dose rate, duration of exposure and mortality probability in total body irradiation in humans. Journal of Biomedical Science and Engineering, 4, 497-505. doi:10.4236/jbise.2011.47063

Chung, S. J. (2011b). Computer program of nonlinear, curved regression for probacent-probability equation in biomedicine. Journal of Biomedical Science and Engineering, 4, 620-630. doi:10.4236/jbise.2011.49078
Chung, S. J. (2012). Computer-assisted formulas predicting cancer mortality after exposure to acute low dose ionizing radiation in humans. Journal of Biomedical Science and Engineering, 5, 180-189. doi:10.4236/jbise.2012.54023

Dresp-Langley, B., \& Durup, J. (2012). Does consciousness exist independently of present time and present time independently of consciousness? Open Journal of Philosophy, 2, 45-49. doi:10.4236/ojpp.2012.21007

Gaynesford, M. (2006). The meaning of the first person term. Oxford: Oxford University Press. doi:10.1093/0199287821.001.0001

Greene, J. D., Sommerville, R. B., Nystrom, L. E., Darley, J. M., \& Cohenm, J. D. (2001). An fMRI investigation of emotional engagement in moral judgement. Science, 293, 2105-2108. doi:10.1126/science.1062872

Gruenberg, L. A. (1959). Defining moment: The Korean War (pp. 2938, 51-63). Detroit, MI: Omnigraphics.

Gusnard, D. A. (2009). Basic science of self. In B. J. Sadock, V. G. Sadock, \& P. Ruiz (Eds.), Kaplan and Sadock's comprehensive textbook of psychiatry (pp. 353-363). New York: Lippincott Williams \& Wilkins.

Hawkins, D. (2002). Powers vs force: The hidden determinants of human behavior (p. 291). Carlsbad, CA: Hay House.

Herman, J. P., Ostlander, M. M., Mueller, N. K., \& Figueiredo, H. (2005). Limbic system mechanisms of stress regulation: Hypothalamus-pi-tuitary-adrenal axis. Progress in Neuro-Psychopharmacology and Biological Psychiatry, 29, 1201-1213. doi:10.1016/i.pnpbp.2005.08.006

Holy Bible (1988). Nashville: Thomas Nelson Publishers.

Hu, X., \& Guo, J. (2011). Evil human nature: From the prospective of St. Augustine and Hsun Tzu. Open Journal of Philosophy, 1, 61-66. doi:10.4236/ojpp.2011.12011

Kluger, J. (2012). Getting to no: The science of building willpower. Times, 5 March 2012, 43-47.

McMillan, M. (2000). An odd kind of fame: Stories of Phineas Gage. Cambridge, MA: MIT Press.

Miller, E. K., \& Cohen, J. D. (2001). An integrative theory of prefrontal cortex function. Annual Review of Neuroscience, 24, 167-202. doi:10.1146/annurev.neuro.24.1.167

Diamond, J. (2007). 1000 events that shaped the world (pp. 18-19). Washington, DC: National Geography Society.

Patent, D. H. (2001). Ch. 14: The reaction to natural selection. In Charles Darwin: The life of a revolutionary thinker (pp. 107-114). New York: Holiday House.

Perlmutter, D., \& Villoldo, A. (2011). Power up your brain: The neuroscience of rnlightenment. New York, NY: Hay House, Inc.

Perlovsky, L. (2012). Free will and advances in cognitive sciences. Open Journal of Philosophy, 1, 32-37. doi:10.4236/ojpp.2012.21005

Playfair, G. L. (2002). Twintelepathy (pp. 38, 92, 94, 121, 147). London: Vega.

Richards, S. S., \& Sweet, R. A. (2009). Alzheimer's disease. In B. J. Sadock, V. G. Sadock, \& P. Ruiz (Eds.), Kaplan \& Sadock's comprehensive textbook of psychiatry (pp. 1176-1185). New York: Lippincott Williams \& Wilkins.

Rilling, J. K., \& Insel, T. R. B. J. (1999) The primate neocortex in comparative perspectiveusing magnetic resonance imaging. Journal of Human Evolution, 37, 191-223. doi:10.1006/jhev.1999.0313

Sapolsky, R. M. (2004). The frontal cortex and the criminal justice system. Philosophical Transactions of the Royal Society of London. Series B, Biological Sciences, 359, 1787-1796. doi:10.1098/rstb.2004.1547

Schultz, W., Tremblay, L., \& Hollerman, J. R. (2000). Reward processing in primate orbitofrontal cortex and basal ganglia. Cerebral Cortex, 10, 272-283. doi:10.1093/cercor/10.3.272

Vacariu, G. (2011). The mind-body problem today. Open Journal of Philosophy, 1, 26-34. doi:10.4236/ojpp.2011.11005

Villoldo, A. (2000). Shaman, healer, sage. New York, NY: Harmony Books.

Wilhelm, R. (Trans.). (1967). The I ching or book of changes (pp. 272, 309). Rendered by C. F. Baynes. London: Rutridge \& Kegan Paul.

Wikipedia (2012). Philosophy of self. 


\section{S. J. CHUNG}

http://en.wikipedia.org/wiki/Philosopy

Yogananda, P. (1946). Autobiography of a yogi. Los Angeles, CA: Self-Realization Fellowship.
Yogananda, P. (1996). Spiritual diary (December 30). Los Angeles, CA: Self-Realization Fellowship. 